\title{
Insulin-like growth factor-1 delays Fas-mediated apoptosis in human neutrophils through the phosphatidylinositol-3 kinase pathway
}

\author{
Eddy Himpe, Céline Degaillier, Astrid Coppens and Ron Kooijman \\ Laboratory of Pharmacology (FARC), Medical School, Vrije Universiteit Brussel (VUB), Laarbeeklaan 103, B1090 Brussels, Belgium \\ (Correspondence should be addressed to E Himpe; Email: eddy.himpe@vub.ac.be)
}

\begin{abstract}
Apoptosis of human neutrophils is a crucial mechanism for the resolution of inflammation. We previously showed that insulinlike growth factor-1 (IGF1) delays spontaneous neutrophil apoptosis without influencing the secretion of cytokines by these cells. In the present study, we further addressed the role of IGF1 in regulating neutrophil survival in the presence of other factors present during inflammation, and the mechanism involved in delaying apoptosis. We show that IGF1 delays neutrophil apoptosis triggered by the agonistic anti-Fas antibody CH11 and that the effect of IGF1 is comparable in magnitude to that of the acknowledged anti-apoptotic cytokines interferon- $\gamma$ (IFNG) and granulocyte-macrophage colony-stimulating factor (GM-CSF; now known as CSF2). Furthermore, IGF1
\end{abstract}

exerted additional effects on cell survival in the presence of these cytokines. IGF1 did not affect Fas expression or activation by anti-Fas of caspase- 8 , but inhibited the depolarization of the mitochondrial membrane. Inhibitor studies indicate that the phosphatidylinositol-3 kinase (PI3K) pathway, but not the MEK-ERK pathway, mediates the effects of IGF1. However, in contrast to CSF2, IGF1 did not induce phosphorylation and translocation to the membrane of AKT, the canonical downstream target of PI3K. We therefore speculate that other downstream targets of PI3K are involved in the delay of neutrophil apoptosis by IGF1, possibly through stabilization of the mitochondrial membrane.

Journal of Endocrinology (2008) 199, 69-80

\section{Introduction}

Neutrophils are pivotal effector cells in the innate immune response. They are phagocytic cells that participate in inflammatory reactions as a first line of defense against invading micro-organisms. Neutrophils are recruited to sites of inflammation by chemoattractants such as interleukin- 8 (IL8). This inflammatory cytokine is produced by monocytes and macrophages, and is also one of the most abundant cytokines produced by neutrophils, which triggers degranulation and oxidative burst, both of which contribute to the destructive properties of these cells (Cassatella 1999). Regulation of the neutrophil life span by apoptosis is a crucial process in the resolution of inflammation, and alterations of apoptosis in neutrophils or their precursors are associated with a number of disorders (Maianski et al. 2004), including neutropenia (Aprikyan et al. 2000, 2001, 2002) and chronic neutrophilic leukemia (Kobayashi et al. 2002).

Neutrophils are programmed for spontaneous apoptosis (the intrinsic apoptotic route). In these cells, this mechanism of apoptosis has special features, probably due to peculiarities of neutrophil mitochondria, which are pivotal for apoptosis (Simon 2003). Importantly, neutrophil apoptosis is highly regulated. Spontaneous apoptosis can be inhibited by inflammatory cytokines, including granulocyte macrophage colony-stimulating factor 2 (GM-CSF; now known as CSF), granulocyte colony stimulating factor 3 (CSF), interferon- $\gamma$ (IFNG) and IL8 (Colotta et al. 1992, Kettritz et al. 1998). On the other hand, the apoptotic process can be stimulated through stimulation of the extrinsic route. This pathway is mainly stimulated by death-inducing receptors belonging to the tumor necrosis factor (TNF)/nerve growth factor (NGF) receptor super-family, such as Fas, TNF-related apoptosisinducing ligand (TNFSF10) receptors, TNFRSF9 (CD137), and the type I TNF receptor (Simon 2003).

In a previous study, we showed that insulin-like growth factor-I (IGF1) delays spontaneous neutrophil apoptosis in serum-free medium (SFM), and that this effect was not mediated by the modulation of cytokine secretion by neutrophils (Kooijman et al. 2002). These findings indicate that IGF1 may be involved in the regulation of neutrophil apoptosis, either through endocrine effects of liver-derived IGF1 under the control of growth hormone (GH1) or via autocrine or paracrine effects. Indeed, IGF1 is produced by cells of the immune system including macrophages (Rom et al. 1988), mitogen-activated peripheral blood mononuclear cells (PBMC) (Nyman \& Pekonen 1993), and stromal cells in bone marrow stromal (Abboud et al. 1991). Since IGF1 production in the immune system is predominantly regulated by cytokines instead of GH1 (Kirstein et al. 1992, Noble et al. 1993, Arkins et al.1995, Fournier et al. 1995), it is possible that IGF1 is part of a cytokine network that modulates the resolution of apoptosis 
through regulation of neutrophil survival. In addition, IGF1 may also be involved in the regulation of inflammatory reactions via effects on neutrophils, because it stimulates superoxide anion production ( $\mathrm{Fu}$ et al. 1991), the uptake of immunoglobulin (IgG) opsonized Staphylococcus aureus, the oxidative burst and degranulation in neutrophils (Bjerknes \& Aarskog 1995). During inflammation, neutrophils are exposed to many factors that can modulate apoptosis, including other cells expressing Fas-ligand, soluble Fas-ligand, and inflammatory cytokines. Some of these factors are able to modulate each other's effects. For instance, it has been shown that CSF2 is able to delay Fas-mediated apoptosis by suppression of Fasassociated protein with dead domain (FADD) recruitment (Kotone-Miyahara et al. 2004) and that activation of TNFRSF9 abrogates the anti-apoptotic effects of CSF2 in neutrophils (Heinisch et al. 2000). It has also been shown that TNF down-regulates TNFRSF9 expression on neutrophils, indicating that the extrinsic route for apoptosis can be inhibited by cytokines (Heinisch et al. 2000). Furthermore, IGF1 also inhibits Fas-mediated apoptosis in T-cells (Walsh \& O'Connor 2000) and neutrophils (Wipke \& Allen 2001), and T-cells (Isaacs 2008) contribute to the pathology of inflammatory diseases like rheumatoid arthritis (RA).

Therefore, we further addressed the role of IGF1 in regulating neutrophil survival in the presence of other factors present during inflammation. We assessed the effects of IGF1 on Fas-mediated induction of apoptosis in the presence or absence of inflammatory cytokines (IFNG or CSF2). We show that IGF1 delays Fas-mediated neutrophil apoptosis via the phosphatidylinositol-3 kinase (PI3K) pathway. In addition, IGF1 inhibits depolarization of the mitochondrial membrane in the presence of $\mathrm{CH} 11$, but does not affect Fas expression and the activation of caspase- 8 . The anti-apoptotic effect of IGF1 was also observed in the presence of antiapoptotic cytokines, indicating that IGF1 could play a role in modulating neutrophil survival during inflammation.

\section{Materials and Methods}

\section{Reagents}

Recombinant human (rh) IGF1 was kindly provided by Lilly Research Laboratories (Indianapolis, IN, USA). Contamination with endotoxin was not detectable using the limulus amebocyte lysate assay (detection limit 1.25 pg/ $\mu \mathrm{g}$; Biowhittaker, Walkersville, MD, USA). The monoclonal antibody against the IGF1 receptor ( $\alpha$ IR3; GR11L) was obtained from Calbiochem (VWR, Leuven, Belgium). CSF2 and IFNG were from PeproTech (London, UK). RPMI, penicillin, and streptomycin were purchased from Invitrogen Life Technologies. U0126, anti-caspase-8 (12F5) and a fluorescein-isothiocyanate (FITC)conjugated IgG3 monoclonal antibody against Fas (APO-1-3) were obtained from Alexis Biochemicals (Zaventem, Belgium). A FITC-labeled isotypic control antibody was obtained from $\mathrm{BD}$ Biosciences Pharmingen (San Diego, CA, USA). The agonistic
anti-Fas immunoglobulin (IgM) monoclonal antibody CH11 was from Upstate (Milton Keynes, UK). BSA (A-2153, Sigma) was of standard grade quality and selected by us because it contained undetectable levels of IGF1 $(<0.05 \mathrm{ng} / \mathrm{mg})$. Wortmannin, cycloheximide, 3-aminopropyltri-ethoxysilane (APES), and JC-1 (5, $5^{\prime}, 6,6^{\prime}$-tetrachloro-1, $1^{\prime}, 3,3^{\prime}$-tetraethylbenzimidazolylcarbocyanine iodide) were also obtained from Sigma. Horseradish peroxidase (HRP)-conjugated donkey anti-rabbit IgG and sheep anti-mouse IgG were obtained from Amersham Pharmacia Biotech. Anti-actin was from Santa Cruz Biotechnology (Boechout, Belgium). Recombinant human TNF and antibodies against phosphorylated AKT $\left(\mathrm{pS}^{473}\right)$, phosphorylated ERK $\left(\mathrm{pTpY}^{185 / 187}\right)$, and total-AKT were obtained from Biosource (Nivelles, Belgium).

\section{Cell preparation and cell culture}

Human neutrophils were purified from heparinized venous blood drawn from healthy donors as described previously (Kooijman et al. 2002). Informed consent was obtained from all blood donors and the research protocol has been approved by the local ethical committee. Freshly isolated neutrophils were suspended in SFM (RPMI 1640 with glutamax-I, supplemented with $0 \cdot 1 \%$ BSA (A-2153), $100 \mathrm{U} / \mathrm{ml}$ penicillin, and $100 \mu \mathrm{g} / \mathrm{ml}$ streptomycin).

For assessment of apoptosis, neutrophils were cultured in $5 \mathrm{ml}$ polystyrene Greiner tubes (Greiner Bio-one, Wemmel, Belgium) for indicated periods of time in a humidified 5\% $\mathrm{CO}_{2}$ atmosphere at $37^{\circ} \mathrm{C}$. IGF1 was added $30 \mathrm{~min}$ before $\mathrm{CH} 11$ and inhibitors were always added $30 \mathrm{~min}$ before the addition of IGF1. At the end of the culture period, $1 \times 10^{5}$ cells were brought onto APES-coated slides and left at room temperature for $30 \mathrm{~min}$ to attach.

For phosphorylation and AKT translocation experiments, neutrophils were treated in eppendorf tubes (Eppendorf AG, Hamburg, Germany) in a prewarmed $\left(37^{\circ} \mathrm{C}\right)$ water bath. Kinase inhibitors or vehicle (dimethylsulfoxide) were always applied $30 \mathrm{~min}$ before the addition of IGF1 or CSF2.

\section{Assessment of apoptosis}

Neutrophils attached to APES-coated slides were fixed and stained with Diff-Quick according to the manufacturer's procedure (Dade Behring S.A., Brussels, Belgium). The proportion of apoptotic neutrophils was determined by light microscopy. Apoptotic neutrophils were defined as cells displaying pyknotic nuclei and diminution of cell volume (Murray et al. 1997). We have previously demonstrated that the effects of IGF1 on apoptotic morphology are in line with DNA fragmentation assay and annexin- $\mathrm{V}$ binding assays (Kooijman et al. 2002).

\section{Flow cytometric analysis of Fas expression}

Neutrophils were suspended in $50 \mu \mathrm{PBS} / 1 \%$ BSA containing $0.25 \mu \mathrm{g}$ anti-Fas antibody (APO-1-3) or an 
isotype-matched control antibody. After $30 \mathrm{~min}$ of incubation at $4{ }^{\circ} \mathrm{C}$, neutrophils were washed twice in PBS and suspended in $50 \mu \mathrm{l}$ PBS. Stained neutrophils were analyzed on a FACS Vantage flow cytometer with a $488 \mathrm{~nm}$ argon laser (Becton Dickinson, Erembodegem, Belgium). For each sample forward light scatter, side scatter and fluorescence of 10000 cells were acquired. Debris and remaining erythrocytes were excluded by gating on the basis of forward and side scatter. Data analysis was performed using WinMDI 2.8 software (URL: http://facs.scripps.edu).

\section{Cytokine measurements}

Neutrophils were separated from the culture medium by centrifugation for $10 \mathrm{~min}$ at $400 \mathrm{~g}$ at room temperature. Culture media were collected and stored at $-20^{\circ} \mathrm{C}$ until use. The levels of IL8, IL1B, TNF, or IL6 were quantified by ELISA using commercial antibody pairs (Cytosets) from Biosource International as described previously (Kooijman et al. 2002). The sensitivities of the ELISA's for IL8, IL1B, TNF, or IL6 were $3,10,4$, and $10 \mathrm{pg} / \mathrm{ml}$ respectively.

\section{Western blotting analysis}

Neutrophils $\left(1.5 \times 10^{6}\right)$ were lysed in $20 \mu$ lice-cold distillated water containing protease inhibitors ( 1 tablet in $5 \mathrm{ml} \mathrm{H} \mathrm{H}_{2} \mathrm{O}$, Roche Diagnostics). Next, $20 \mu$ boiling $2 \times$ concentrated sample buffer was added to the total cell lysate and the samples were boiled for $10 \mathrm{~min}$. SDS-PAGE and transfer were performed as previously described (Kooijman et al. 1997). After blocking for $1 \mathrm{~h}$ at room temperature in blocking buffer (PBS/5\% non-fat dry milk/0.1\% Tween-20), blots were probed with primary antibodies $(1 / 1000$ in $\mathrm{PBS} / 5 \% \mathrm{BSA} /$ $0 \cdot 1 \%$ Tween-20) for $18 \mathrm{~h}$ at $4{ }^{\circ} \mathrm{C}$. Blots were washed three times for $10 \mathrm{~min}$ in PBS $/ 0 \cdot 1 \%$ Tween-20 and incubated with a species-specific HRP-labeled IgG (1/5000 in blocking buffer) for $1 \mathrm{~h}$ at room temperature. After washing, immunoreactive bands were detected using enhanced chemiluminescence (Perkin-Elmer, Boston, MA, USA). To check for equal loading, blots were stripped by incubation in $0.25 \mathrm{M} \mathrm{NaOH}$ at room temperature and incubated with polyclonal antibody against actin. Densitometric analysis was performed using Scion Image (Scion Corporation, Frederick, MO, USA).

\section{Depolarization of the mitochondrial membrane}

After cell culture in SFM, JC-1 was added in a final concentration of $9 \mu \mathrm{M}$. After $5 \mathrm{~min}$ incubation at $37^{\circ} \mathrm{C}$, the cells were washed with PBS and centrifuged $(200 \mathrm{~g})$ for 5 min. Subsequently, the cells were resuspended in PBS and analyzed with the FACS Vantage flow cytometer. For each sample forward light scatter, side scatter, FL1 and FL2 of 10000 cells were acquired. Debris and remaining erythrocytes were excluded by gating on the basis of forward and side scatter. The cells were analyzed with WinMDI 2.8 software.

\section{AKT translocation assays}

Neutrophils were isolated and resuspended at a final concentration of $40 \times 10^{6}$ in $500 \mu \mathrm{l}$ SFM. After $30 \mathrm{~min}$ preincubation at $37^{\circ} \mathrm{C}$, the cells were treated with SFM,

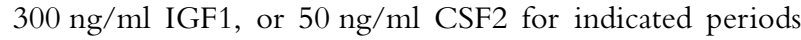
of time. The reaction was stopped by adding ice cold buffer $(100 \mathrm{mM} \mathrm{KCl}, 50 \mathrm{mM}$ HEPES, $5 \mathrm{mM} \mathrm{NaCl}, 1 \mathrm{mM} \mathrm{MgCl}$, $0.5 \mathrm{mM}$ EDTA, $5 \mu \mathrm{g} / \mathrm{ml}$ aprotinin, $5 \mu \mathrm{g} / \mathrm{ml}$ leupeptin, $1 \mathrm{mM}$ activated orthovanadate, $0 \cdot 25 \mathrm{mM}$ (4-(2-aminoethyl) benzenesulfonyl fluoride hydrochloride). The suspension was sonicated for $20 \mathrm{~s}$ and centrifuged for $10 \mathrm{~min}$ at $15000 \mathrm{~g}$. Supernatants were collected and centrifuged for $2 \mathrm{~h}$ at $50000 \mathrm{~g}$ in a Beckman Avanti J25 centrifuge with a JA20 rotor. All membrane material in the pellets, obtained from $40 \times 10^{6}$ cells, was analyzed by western blotting using an $8 \cdot 5 \%$ gel. Unequal loading of the gel was corrected by quantifying the amounts of actin on the western blot.

\section{Statistical analysis}

To determine statistical significance, repeated-measures ANOVA with a Bonferroni multiple comparison post-test was used (Figs 1 and 5C). The one-sample $t$-test with a Bonferroni correction for multiple comparisons was used to assess whether relative increase in the percentage of apoptotic neutrophils was significantly different from the control values, which were put at $100 \%$ (Fig. 2). In other experiments, the two-tailed unpaired $t$-test was used. Means were considered to be statistically different at $P$ values $<0 \cdot 05$.

\section{Results}

\section{Inhibition of spontaneous and Fas-mediated apoptosis}

We measured apoptosis in freshly isolated neutrophils by morphological evaluation. After $5 \mathrm{~h}$ of culture, the percentage of apoptotic neutrophils increased with $12 \cdot 1 \%$ from $2 \cdot 7 \%$ at $t=0$ to $14 \cdot 8 \%$ (spontaneous apoptosis) at $5 \mathrm{~h}$. To test the effects of IGF1 on Fas-mediated apoptosis, we incubated neutrophils with $100 \mathrm{ng} / \mathrm{ml}$ of the anti-Fas antibody CH11. This concentration of $\mathrm{CH} 11$ has been shown to stimulate Fasmediated apoptosis in neutrophils. It activates caspase-8 (Kotone-Miyahara et al. 2004, Iwase et al. 2006) and it evokes the recruitment of FADD to Fas (Kotone-Miyahara et al. 2004). Indeed, stimulation of the extrinsic pathway by CH11 further increased the percentage of apoptotic neutrophils to $39.6 \%$ in the absence of IGF1 and to $18.5 \%$ in the presence of IGF1 (Fig. 1C). Although CH11 activates the extrinsic apoptotic pathway, one may not exclude the possibility that the intrinsic route, involved in spontaneous apoptosis, is still operative. However, since the anti-apoptotic effects of IGF1 in the absence of CH11 are much smaller than those in the presence of CH11, the effect of IGF1 on CH11treated neutrophils is at least in part due to the inhibition of 

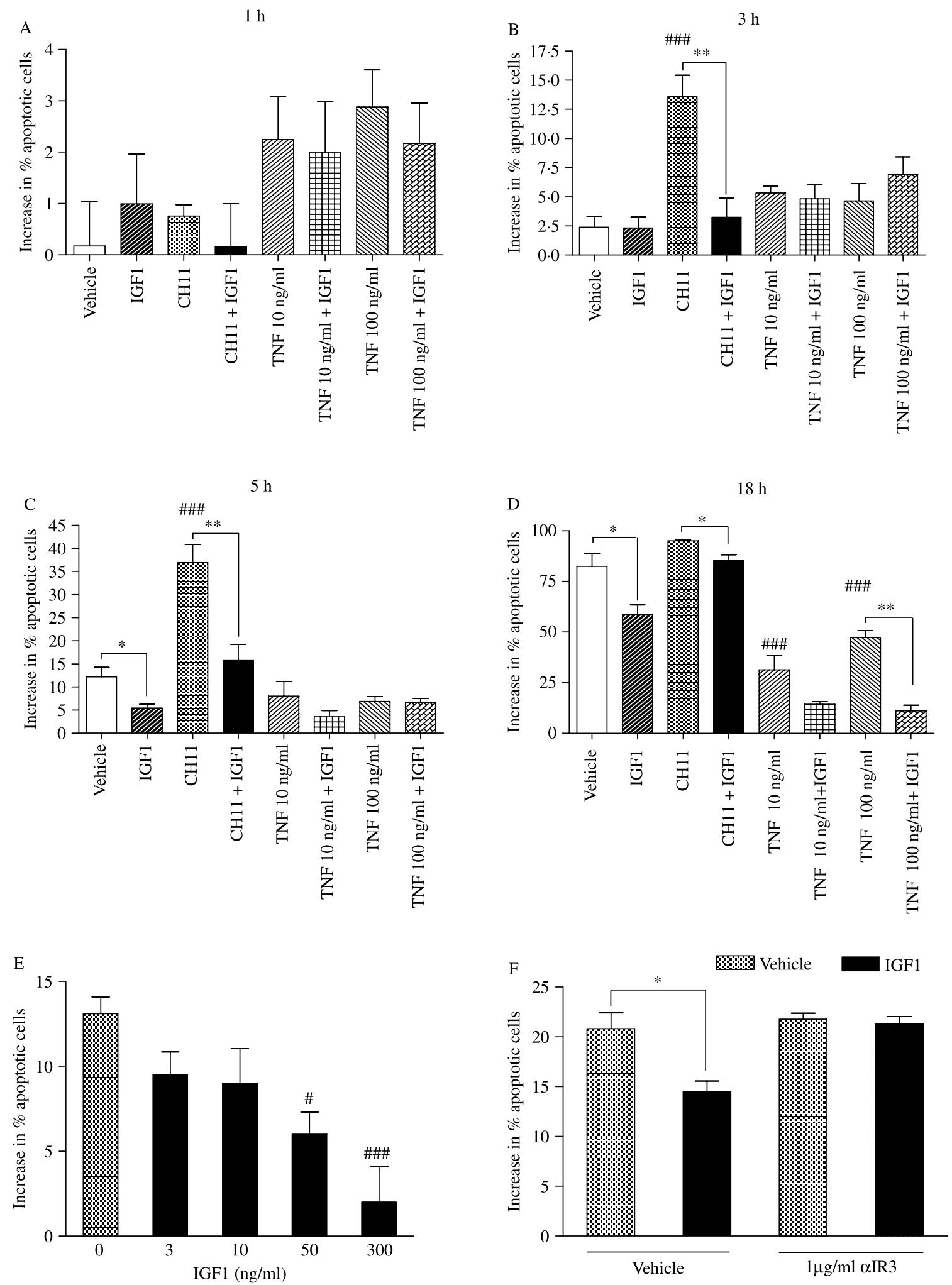
Fas-mediated apoptosis. After $18 \mathrm{~h}$ of incubation (Fig. 1D), the effects of IGF1 on spontaneous and Fas-mediated apoptosis are relatively less compared with the effects after $5 \mathrm{~h}$. To assess whether IGF1 can also delay the effects of other death-inducing signals, we tested the effects of IGF1 in the presence of TNF. However, we found that TNF augmented spontaneous apoptosis during the first $3 \mathrm{~h}$ of the culture period (Fig. 1A and B), although these effects did not reach significance. In contrast, at $18 \mathrm{~h}$ spontaneous apoptosis was significantly reduced by TNF. Addition of IGF1 resulted in a further reduction in the increase of apoptotic cells (Fig. 1D). The differential effects of TNF on early time points compared with $18 \mathrm{~h}$ are in line with observations from others (Murray et al. 1997). In contrast, the rate of neutrophil apoptosis in our culture system is higher than that shown by Murray et al. (1997), probably due to the use of SFM instead of serumcontaining media.

The dose-response curve in Fig. 1E shows that physiological concentrations of IGF1 effectively inhibit Fasmediated apoptosis. The inhibitive effects of a blocking antibody against the IGF1R, and our finding that insulin was without effect (data not shown) indicate that the effects of IGF1 are mediated by the IGF1R (Fig. 1F).

\section{Anti-apoptotic effects of IGF1, IFNG and CSF2}

The anti-apoptotic effects of cytokines have predominantly been assessed in the presence of serum, and thereby in the presence of IGF1 and other factors. To evaluate their independent effects and possible synergistic interactions with IGF1, we cultured neutrophils in SFM with IGF1, CSF2, IFNG or combinations thereof. Figure 2 reveals that IGF1 and both cytokines significantly inhibit Fas-mediated apoptosis, and it appeared that the anti-apoptotic effects of IGF1 were comparable to those of CSF2 and IFNG. The average inhibition of apoptosis by $300 \mathrm{ng} / \mathrm{ml} \mathrm{IGF1,} 1 \mathrm{ng} / \mathrm{ml}$ CSF2 (Fig. 2A), and $2 \mathrm{ng} / \mathrm{ml}$ IFNG (Fig. 2B) in seven independent experiments was 44,51 , and $47 \%$ respectively. It also appeared that IGF1 has the potential to inhibit Fasmediated apoptosis when neutrophils are exposed to CSF2 or IFNG at concentrations that effectively inhibit apoptosis. In the presence of $2 \mathrm{ng} / \mathrm{ml}$ IFNG or $1 \mathrm{ng} / \mathrm{ml} \mathrm{CSF2,} \mathrm{IGF1}$ significantly reduced apoptosis by 58 and 44\% respectively. Remarkably, at higher concentrations of IFNG or CSF2 the effects of IGF1 were smaller and not significant.

\section{IGF1 does not modulate cytokine production by neutrophils}

Pro-inflammatory cytokines such as IL8, IL6, TNF, and IL1B could mediate the anti-apoptotic effect of IGF1. Recently, it has been shown that the inhibition by TNF of spontaneous neutrophil apoptosis was mediated by the increase in IL8 production (Cowburn et al. 2004). To address this issue, we measured the effect of IGF1 on the secretion of cytokines by neutrophils exposed to SFM (vehicle), CH11, and TNF (10, $100 \mathrm{ng} / \mathrm{ml})$. CH11 and IGF1 had no effect on the secretion by neutrophils of IL8 (Fig. 2C), TNF, or IL1B (data not shown) during the first $5 \mathrm{~h}$ of culture. After $18 \mathrm{~h}$, however, IL8 levels in the culture medium of CH11-stimulated cells were reduced by IGF1. IL6 levels in the conditioned media were below the detection limit.

\section{IGF1 does not affect Fas expression and caspase- 8 activation in neutrophils}

Having established anti-apoptotic effects of IGF1 on Fasmediated neutrophil apoptosis, we next sought to investigate whether these effects are mediated by the modulation of Fas expression. Indeed, IGF1 has been shown to modulate Fas expression on the cell surface of several cell types. For instance, in osteoblasts IGF1 stimulates Fas expression (Kawakami et al. 1998), whereas IGF1 down-regulates the expression of Fas in PHA-activated cord blood $\mathrm{T}$ cells ( Tu et al. 2000). We assessed the effects of IGF1 on Fas expression in neutrophils by flow cytometry. The histogram in Fig. 3A confirms the observation of others (Iwai et al. 1994, Liles et al. 1996, Kotone-Miyahara et al. 2004) that neutrophils express Fas. As shown in Fig. 3B, IGF1 does not influence cell surface expression of Fas on neutrophils. IGF1 has been shown to upregulate Flice (caspase-8) inhibiting protein (Flip), which interferes with the signaling of death-inducing receptors through blocking the association of caspase- 8 with the intracellular domain of these receptors (Mitsiades et al. 2003). Therefore, it is conceivable that IGF1 interferes with

Figure 1 IGF1 delays neutrophil apoptosis. Apoptotic cells were assessed morphologically directly after isolation of neutrophils $(t=0)$ and after indicated culture periods in SFM. Values in the histograms represent the increase in the percentage of apoptotic cells during the culture period (A-D). Cells were cultured in the absence of stimuli, in the presence of either IGF1 (300 ng/ml), CH11 (100 ng/ml), or TNF (10, $100 \mathrm{ng} / \mathrm{ml})$, or in the presence of $\mathrm{CH} 11$ and IGF1 or TNF and IGF1. Vehicle (SFM) or IGF1 was added at the start of the culture. After 30 min, CH11 or TNF $(10,100 \mathrm{ng} / \mathrm{ml})$ were added and the cells were further cultured for indicated periods of time. Values are mean \pm S.E.M. from quadruplicate incubations. This experiment is representative of three independent experiments using different blood donors. To determine the statistical significance of IGF1 effects, a two-tailed unpaired $t$-test was used. ${ }^{*} P<0 \cdot 05 ; * * P<0 \cdot 01 ; * * * P<0 \cdot 001$. To determine the effect of CH11 or TNF alone versus vehicle, an ANOVA with a Bonferroni multiple comparison post-test was used. $\# \# P<0 \cdot 001$ (E). Dose-response curve for inhibition of Fas-mediated apoptosis by IGF1. The cells were treated with $\mathrm{CH} 11$ and IGF1 as described in Fig. 1A-D and cultured for $5 \mathrm{~h}$ after addition of $\mathrm{CH} 11$. Values are mean \pm S.E.M. from quadruplicate incubations and representative of four independent experiments. ${ }^{\#} P<0 \cdot 05$; ${ }_{\# \#} P<0.001$ significantly different from the vehicle. (F) Abrogation of the anti-apoptotic effect of IGF1 by an antibody against the IGF1 receptor (aIR3). Neutrophils were treated with $\mathrm{CH} 11$ and IGF1 as described for Fig. 1A-D and cultured for 5 h. Part of the cells were pre-incubated with $1 \mu \mathrm{g} / \mathrm{ml} \mathrm{\alpha IR} 3$ for $30 \mathrm{~min}$ prior to the addition of IGF1 or vehicle. Values are mean \pm s.E.M. from quadruplicate incubations and representative of three independent experiments using different blood donors. ${ }^{*} P<0 \cdot 05$. 

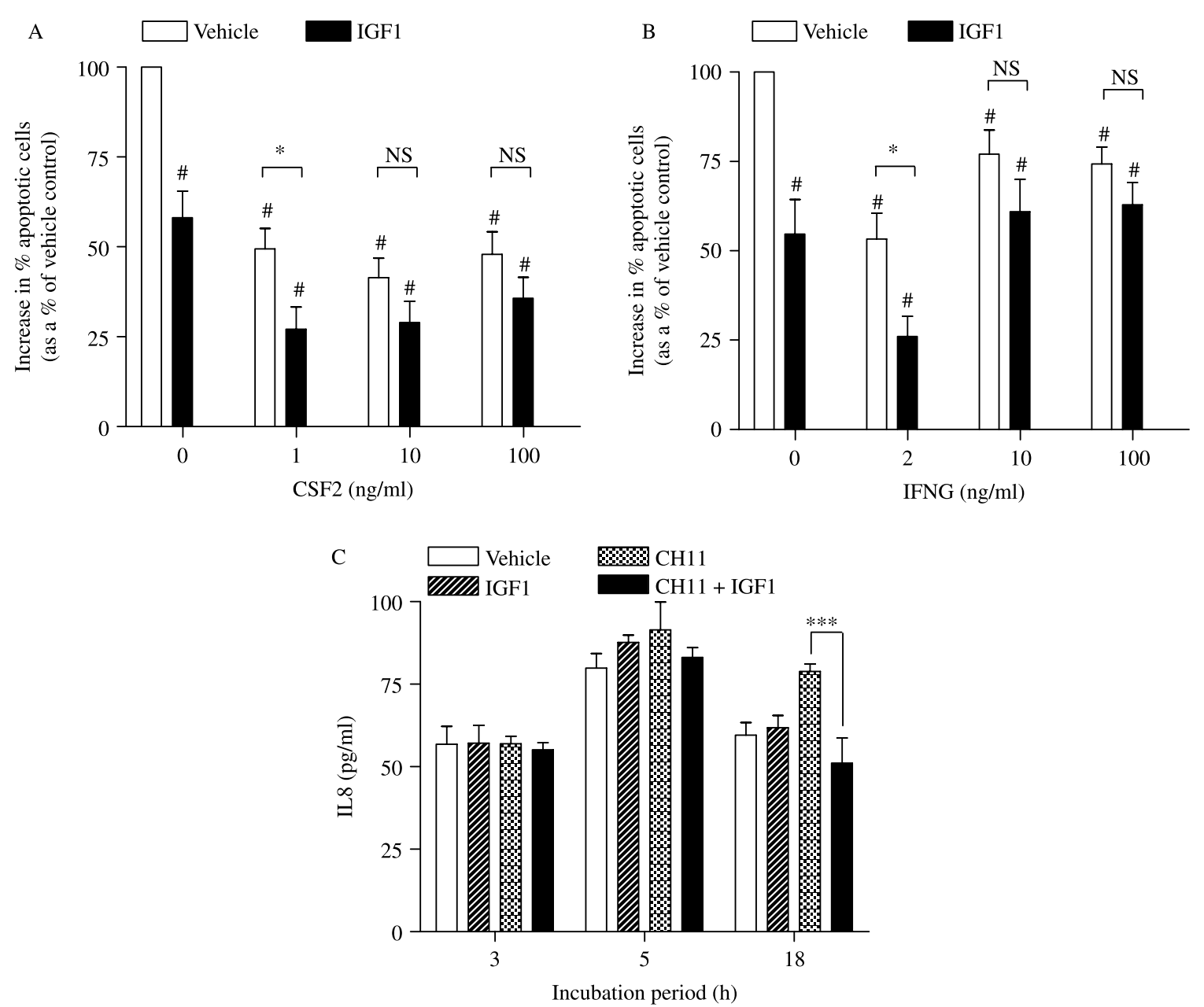

Figure 2 Inhibition of Fas-mediated apoptosis by 300 ng/ml IGF1 in the absence or presence of (A) CSF2 or (B) IFNG. IGF1, CSF2, INFG, or combinations thereof were added $30 \mathrm{~min}$ before the addition of $100 \mathrm{ng} / \mathrm{ml} \mathrm{CH} 11$. Subsequently, cells were incubated for $5 \mathrm{~h}$ in the presence of $\mathrm{CH} 11$, after which apoptosis was assessed morphologically. The increase in the fraction of apoptotic cells is expressed as a percentage of the control (no cytokine, no IGF1). \#=Statistically different from the control ( $100 \%$, $P<0 \cdot 05)$. Data represent mean \pm S.E.M. of seven independent experiments using different blood donors. ${ }^{*}=$ Significant effect of IGF1 $(P<0 \cdot 05)$; NS = not significant. (C) Effect of IGF1 on IL8 production. Neutrophils were incubated for indicated periods of time with vehicle, IGF1 $(300 \mathrm{ng} / \mathrm{ml}), \mathrm{CH} 11(100 \mathrm{ng} / \mathrm{ml})$, or $\mathrm{CH} 11$ and IGF1. Values are mean \pm s.E.M. of quadruplicate incubations. This experiment is representative of three independent experiments using different blood donors. ${ }^{* * *} P<0 \cdot 001$.

the extrinsic apoptotic pathway through inhibition of caspase- 8 activation. Binding of $\mathrm{CH} 11$ to Fas results in the binding and cleavage of full caspase- 8 , leading to the expression of the small active caspase- 8 fragment (p18) that can be detected by western blotting. Figure $4 \mathrm{~A}$ shows that caspase- 8 cleavage is stimulated by CH11. In contrast to CSF 2 that is known to inhibit caspase-8 cleavage (Watson et al. 1999, Kotone-Miyahara et al. 2004), IGF1 did not inhibit the cleavage of caspase-8 (Fig. 4A).

\section{IGF1 partially blocks the destabilization of the mitochondrial membrane}

Depolarization of the outer mitochondrial membrane is key to the activation of the intrinsic apoptotic pathway triggered by stress factors. In addition, depolarization may also occur in Fasmediated apoptosis via truncation of the B-cell lymphoma 2 (BCL2) family protein Bid by activated caspase-8. We therefore assessed the effect of IGF1 on membrane depolarization by flow cytometric analysis using the fluorescent indicator JC-1. At a high mitochondrial membrane potential, JC-1 forms aggregates in the mitochondria and emits red fluorescence with a maximum at $590 \mathrm{~nm}$. Monomers emitting green fluorescence (maximal emission at $527 \mathrm{~nm}$ ) are formed at low membrane potential. It appeared that, cultured neutrophils comprise two fractions, one with an intermediate level of green fluorescence and then the other with high-level representing cells with a normal mitochondrial membrane potential and cells with a depolarized membrane respectively. As depicted in Fig. 4C, stimulation with $\mathrm{CH} 11(100 \mathrm{ng} / \mathrm{ml})$ for $3 \mathrm{~h}$ increased the 
A

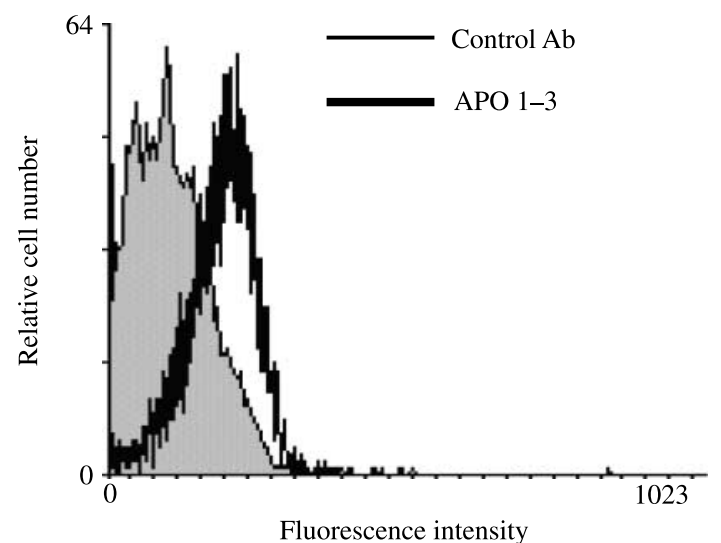

B

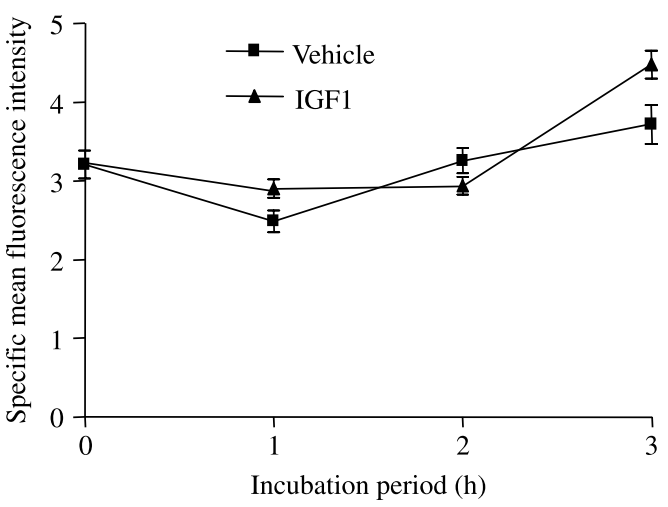

Figure 3 IGF1 does not affect cell surface expression of Fas on neutrophils. (A) Histogram of APO-1-3-stained freshly isolated neutrophils superimposed over the histogram of neutrophils stained with an irrelevant isotopic matched antibody.

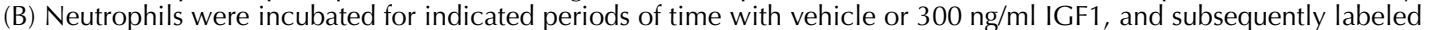
with a fluorescein-conjugated antibody against Fas (APO-1-3) for flow cytometric analysis. This graph shows the effects of IGF1 on the specific mean fluorescence intensity (MFI) of APO-1-3-stained neutrophils. Specific MFI was calculated by subtracting the MFI of controls from the MFI of APO-1-3-stained neutrophils. Values are mean \pm S.E.M. of quadruplicate incubations. This experiment is representative of four independent experiments using different blood donors.

percentage of cells with a high level of green fluorescence. Figure 4D shows the effects on the level of green fluorescence after stimulation for $5 \mathrm{~h}$ with SFM, IGF1, CH11 or CH11 and IGF1. CH11 increased the percentage of cells showing mitochondrial membrane depolarization, after 3,4 and $5 \mathrm{~h}$ of culture. In addition, IGF1 decreased the fraction of these cells in the presence of CH11 (Fig. 4B). Taken together our results suggest that the anti-apoptotic effect of IGF1 in CH11-treated neutrophils is mediated, at least in part, by stabilization of the mitochondrial membrane.

\section{IGF1 signaling pathways}

To address the role of two principal IGF1R signaling routes, the PI3K pathway and the MEK-ERK pathway, we incubated neutrophils with different kinase inhibitors. Figure 5A shows that the inhibition of apoptosis by IGF1 is completely abrogated in the presence of the PI3K inhibitor wortmannin, whereas the effect of IGF1 is hardly or not affected by the MEK inhibitor U0126. Phosphorylation studies revealed that IGF1 does not influence the phosphorylation of MAPK1 nor that of the PI3K downstream target AKT, whereas CSF2 augmented the phosphorylation of these kinases markedly (Fig. 5B and C). These results confirm that the MEK-ERK pathway is not involved and indicates a role for PI3K targets other than AKT. Activation of PI3K leads to the generation of phosphatidylinositol triphosphate (PIP3), which functions as a docking site for AKT and other proteins through their pleckstrin homology $(\mathrm{PH})$ domains (Takesono et al. 2002). To confirm that AKT is not involved in IGF1 signaling, we assessed the translocation of AKT in response to IGF1 and CSF2. Since translocation of AKT precedes its activation through phosphorylation at the membrane, we assessed translocation at several time points between $20 \mathrm{~s}$ and $10 \mathrm{~min}$. We found CSF2 to evoke the recruitment of AKT to the membrane, while IGF1 had no effect (Fig. 5D and E).

\section{Discussion}

Apoptosis in neutrophils is pivotal to the resolution of inflammation (Savill 1997). Interestingly, neutrophils display several special features with respect to apoptosis. The mitochondrion, which does not seem to be required for energy supply, appears to be specialized in the regulation of apoptosis, and glucocorticoids inhibit apoptosis in neutrophils, whereas in other cell types, including eosinophils, they induce apoptosis. Another special feature of neutrophils is that these cells are subject to spontaneous apoptosis. When neutrophils leave the bone marrow environment, they have a circulating half-life of $6-10 \mathrm{~h}$. However, it should be stressed that neutrophil apoptosis during inflammation is highly regulated by several pro- and anti-apoptotic factors in the surrounding milieu. It has been described by many groups that inflammatory cytokines inhibit apoptosis (Maianski et al. 2004), which may lead to enhanced neutrophils survival during inflammation. On the other hand, ligands engaging so-called death receptors of the TNF/NGF receptor superfamily are able to stimulate neutrophil apoptosis (Simon 2003). Although the effects of many apoptosis-regulating agents are known, the molecular mechanism involved in the orchestration of neutrophils survival remains to be established.

In a previous study, we showed that IGF1 delays spontaneous apoptosis of human neutrophils in SFM (Kooijman et al. 2002). Although neutrophils secreted low 
A

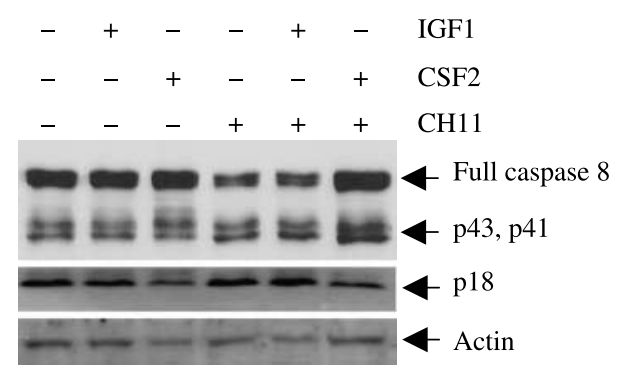

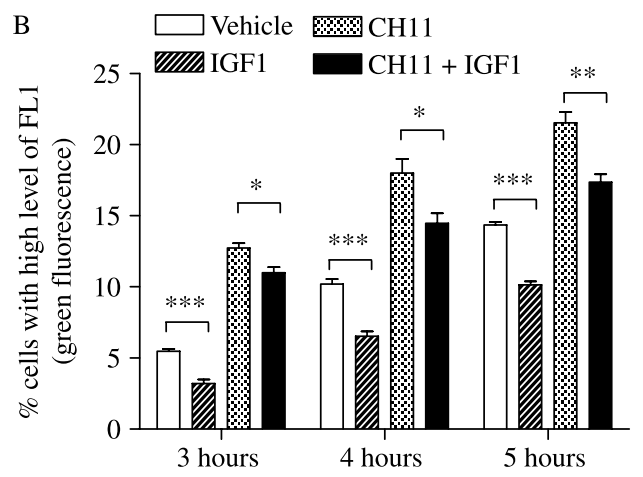

C
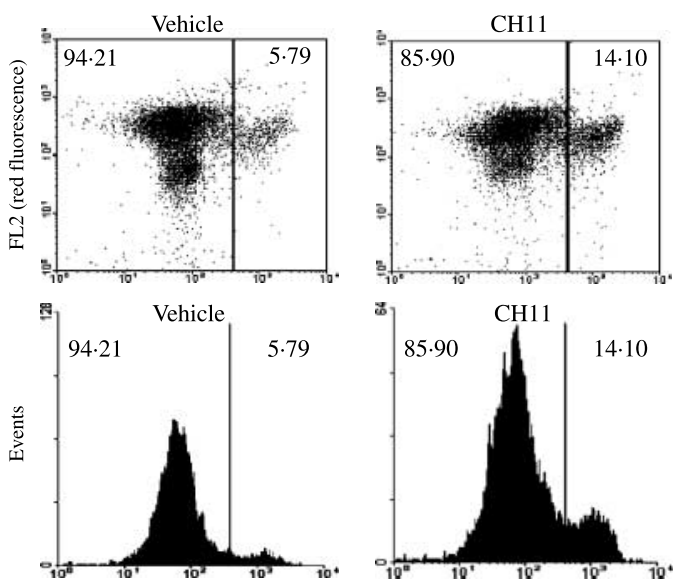

FL1 (green fluorescence)
$\mathrm{D}$
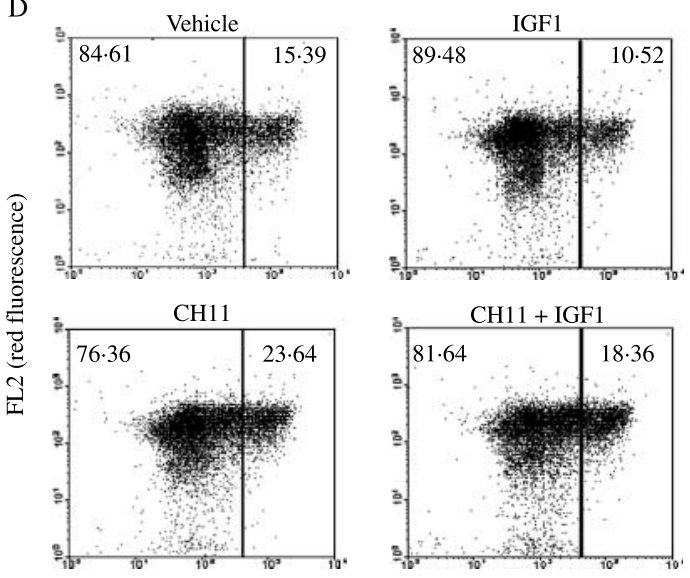

FL1 (green fluorescence)

Figure 4 IGF1 does not affect caspase-8 activation but partially blocks the destabilization of the mitochondrial membrane. (A) Effects of IGF1 and CSF2 on caspase- 8 activation. Cells were pre-incubated for $30 \mathrm{~min}$ with $20 \mu \mathrm{g} / \mathrm{ml}$ cycloheximide (CHX) to facilitate the activation of caspase-8. Subsequently, the cells were treated for 30 min with vehicle, IGF1 (300 ng/ml) or CSF2 $(50 \mathrm{ng} / \mathrm{ml})$, after which they were cultured for $5 \mathrm{~h}$ in the presence or absence of $100 \mathrm{ng} / \mathrm{ml} \mathrm{CH} 11$. Activation of caspase-8 was measured by assessing the cleavage of full caspase- 8 by western blot analysis of $1.5 \times 10^{6}$ cells. The immunoblot of the cleaved fragment (p18) was exposed to the chemiluminescence reaction for a longer period $(60 \mathrm{~min})$ than the immunoblot of full caspase- 8 and the intermediate fragments p43/p41 (5 min). To check for equal loading, blots were stripped and incubated with the polyclonal antibody against actin (lower panel). This result is representative of three independent experiments using different blood donors. (B) Neutrophils were pre-incubated for $30 \mathrm{~min}$ with vehicle or $300 \mathrm{ng} / \mathrm{ml}$ IGF1 and subsequently cultured for 3, 4, and $5 \mathrm{~h}$ in the presence or absence of $\mathrm{CH} 11(100 \mathrm{ng} / \mathrm{ml})$. Mitochondrial membrane depolarization was assessed by flow cytometry using JC- 1 as a membrane potential sensitive dye. The percentage of cells with high levels of green fluorescence (FL1) was determined. Treatment with the $\mathrm{K}^{+}$-ionophore valinomycine resulted in loss of membrane potential in virtually all cells (not shown). Values are mean \pm S.E.M. of quadruplicate incubations. This experiment is representative of three independent experiments using different blood donors. ${ }^{*} P<0 \cdot 05 ;{ }^{* *} P<0 \cdot 01 ;{ }^{* *} P<0 \cdot 001$. (C) Dot-plots of the primary data from a representative experiment. The dot-plots and corresponding histograms show the increase in neutrophils with high levels of green fluorescence after stimulation with $\mathrm{CH} 11(100 \mathrm{ng} / \mathrm{ml})$ for $3 \mathrm{~h}$. (D) Dot-plots representing primary data from neutrophils incubated for $5 \mathrm{~h}$ with vehicle, IGF1, CH11 or $\mathrm{CH} 11$ and IGF1. The numbers in $\mathrm{C}$ and D indicate the percentage of cells with intermediate and high FL1 levels respectively.

levels of inflammatory cytokines, they did not mediate the effects of IGF1. However, during inflammation, neutrophils are exposed to large amounts of cytokines produced by monocytes and lymphocytes, and to FASLG (Fas-ligand) expressed on activated $\mathrm{T}$ cells or secreted into the milieu by macrophages after ingestion of apoptotic neutrophils. It has been shown that IGF1 inhibits Fas-mediated apoptosis in T-cells (Walsh \& O'Connor 2000) and that there is a reduced susceptibility to Fas-mediated apoptosis in peripheral blood
T-cells from patients with RA (Szodoray et al. 2003). Removal of neutrophils protects mice from joint-specific inflammation in a murine model of RA showing the important role of neutrophils (Wipke \& Allen 2001) in RA. Elevated levels of IGF1 are reported in synovial fluid from patients with osteoarthritis, RA (Matsumoto et al. 1996) or in lung tissues from patients with acute respiratory distress syndrome (Krein et al. 2003), all diseases where delayed neutrophil apoptosis contributes to the disease. To establish 


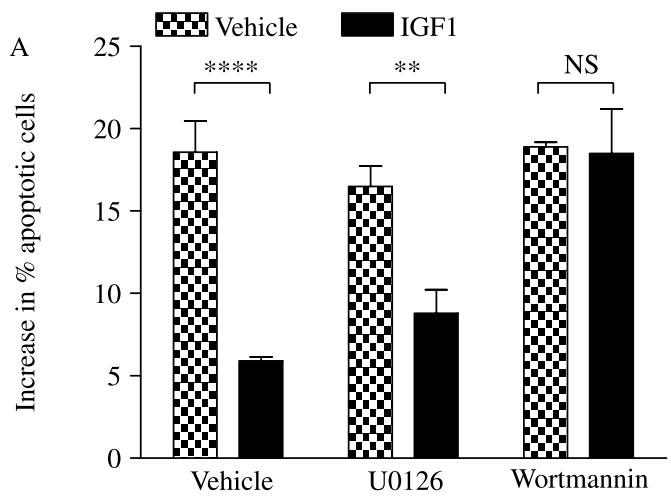

B
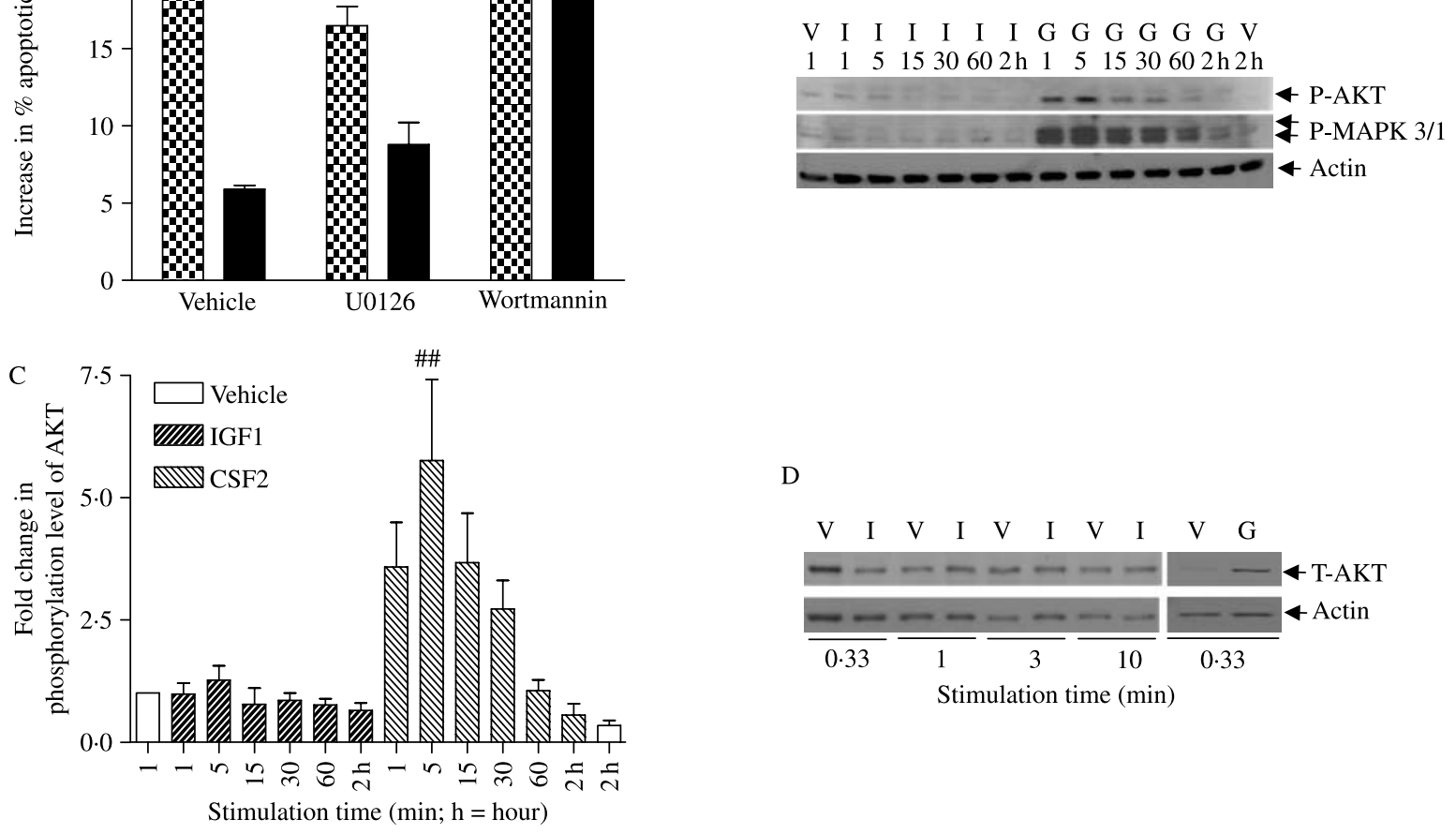

$\mathrm{D}$
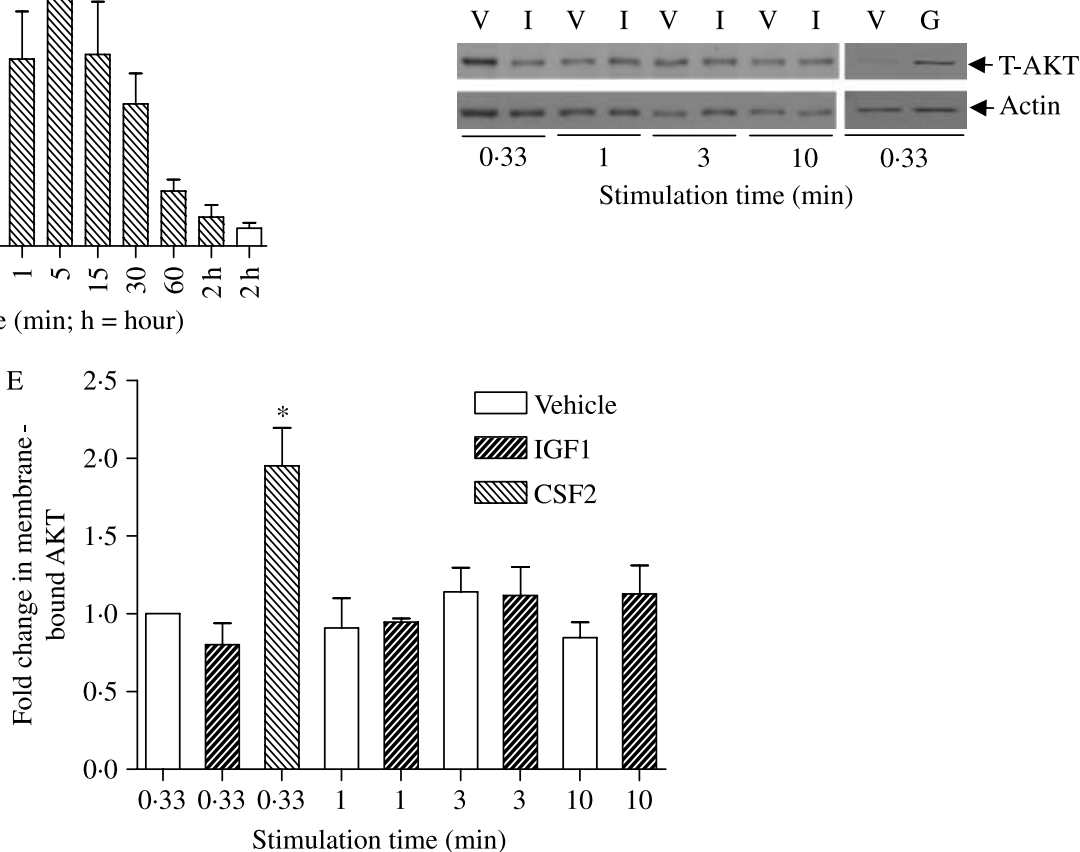

Figure 5 IGF1 signaling pathways. (A) Inhibition of the anti-apoptotic effects of IGF1 by the PI3K inhibitor wortmannin. Neutrophils were pre-incubated for $30 \mathrm{~min}$ with vehicle (DMSO), $0 \cdot 03 \mu \mathrm{M}$ wortmannin, or $1 \cdot 0 \mu \mathrm{MU} 0126$, and subsequently treated with vehicle or IGF1 for $30 \mathrm{~min}$. Next, CH11 (100 ng/ml) was added and cells were cultured for $5 \mathrm{~h}$ in the presence of $\mathrm{CH} 11$. Apoptosis was analyzed morphologically. Values are mean \pm S.E.M. of quadruplicate incubations. This result is representative of four independent experiments using different blood donors. ${ }^{* *} P<0 \cdot 01 ;{ }^{* * *} P<0 \cdot 001$; NS $=$ not significant. (B) Effects of IGF1 and CSF2 on phosphorylation of AKT and MAPK1 were assessed by immunoblotting using phospho-specific antibodies. Before each phosphorylation experiment, neutrophils were pre-incubated for $60 \mathrm{~min}$ in SFM. Then, neutrophils were stimulated for indicated periods of time (minutes; $\mathrm{h}=$ hour) with vehicle (V), $300 \mathrm{ng} / \mathrm{ml} \mathrm{IGF1} \mathrm{(I),} \mathrm{or} 50 \mathrm{ng} / \mathrm{ml} \mathrm{CSF2} \mathrm{(G).} \mathrm{Phosphorylation} \mathrm{of} \mathrm{kinases} \mathrm{was} \mathrm{assessed}$ using phospho-specific antibodies. To check for equal loading, blots were stripped and incubated with the polyclonal antibody against actin (lower panel). This experiment is representative of three independent experiments using different blood donors. (C) The histogram represents the fold change in the phosphorylation level of AKT versus vehicle $1 \mathrm{~min}$, normalized against actin. Values are mean \pm s.E.M. from three (IGF1) or four (CSF2) independent experiments using different blood donors. ${ }^{\#} P<0 \cdot 01$. (D) Effects of IGF1 and CSF2 on the recruitment of AKT to the membrane. Neutrophils were pre-incubated for $30 \mathrm{~min}$ in SFM and subsequently stimulated with vehicle $(\mathrm{V})$, $300 \mathrm{ng} / \mathrm{ml} \mathrm{IGF1} \mathrm{(I),} \mathrm{or} 50 \mathrm{ng} / \mathrm{ml} \mathrm{CSF2} \mathrm{(G).} \mathrm{Membranes} \mathrm{were} \mathrm{isolated} \mathrm{by} \mathrm{differential} \mathrm{centrifugation,} \mathrm{after} \mathrm{which} \mathrm{the} \mathrm{amount} \mathrm{of} \mathrm{AKT} \mathrm{was}$ measured by western blot analysis. To confirm equal amount of loading, the membranes were reblotted with a polyclonal antibody against actin. (E) The histogram represents the fold-change in membrane-bound AKT normalized against actin. Values are mean \pm S.E.M. from three independent experiments using different blood donors. To determine the effect of CSF2 versus vehicle (20 s), a onesample $t$-test with a Bonferroni multiple comparison post-test was used. ${ }^{*} P<0 \cdot 05$. 
the potential role of IGF1 in the regulation of neutrophil apoptosis during inflammation, we studied the effects of IGF1 in the presence of pro- or anti-apoptotic signals. Inhibition of Fas-mediated apoptosis by IFNG, CSF2, CSF3, and TNF has been previously reported (Liles et al. 1996, Watson et al. 1999, Kotone-Miyahara et al. 2004). To explore the possible interactions between IGF1 and anti-apoptotic cytokines, we assessed the effects of IGF1 on Fas-stimulated apoptosis in the presence of CSF2 or IFNG. Our results demonstrate that the inhibitory effects of CSF2 and IFNG do not depend on the presence of IGF1. Since IGF1 delays apoptosis not only in SFM but also in the presence of the established antiapoptotic cytokines CSF2 or IFNG, we believe that IGF1 has the potential to inhibit neutrophil apoptosis during inflammation. However, at high concentrations of IFNG or CSF2, the inhibitive effect of IGF1 was partially abrogated. Especially, high concentrations of IFNG, which were also less effective in reducing apoptosis in the absence of IGF1, almost completely blocked the effect of IGF1. The role of this phenomenon during inflammation and the mechanism involved remain to be established. An intriguing question is whether IGF1 is involved in the orchestration of neutrophil apoptosis during inflammation. IGF1 may mediate certain effects of cytokines during inflammation, because it can be produced by macrophages (Rom et al. 1988, Arkins et al. 1993) and regulated by inflammatory cytokines including TNF (Noble et al. 1993) and IL1B (Kirstein et al. 1992). Furthermore, several authors demonstrated that the Th1 cytokine INFG inhibits IGF1 production in macrophages (Kirstein et al. 1992, Arkins et al. 1995), whereas the Th2 cytokines IL4 and IL13 stimulate IGF1 production in these cells (Wynes \& Riches 2003). The last observation prompted the authors to speculate that Th1 cytokines inhibit IGF1 expression in macrophages, while Th2 cytokines enhance IGF1 expression. However, the specific role of IGF1 in regulating neutrophil apoptosis during Th1 and Th2 immune responses remains to be established. Another argument for a regulatory role of IGF1 in neutrophil apoptosis is provided by the observation that two neutrophil proteases, cathepsin $G$ and elastase, effectively cleave all six well-characterized IGFbinding proteins (IGFBPs; Gibson \& Cohen 1999). Proteolytic cleavage of IGFBPs leads to the release of sequestrated IGF1, increasing the concentration of free IGF1 (Firth \& Baxter 2002).

We show that IGF1 delays Fas-mediated apoptosis and that IGF1 and TNF have the same potency to delay spontaneous neutrophil apoptosis. Moreover, the additive effect of IGF1 on TNF-inhibited spontaneous apoptosis can be interesting because several inflammatory diseases are now treated with an anti-TNF antibody to prevent TNF binding to its receptor. This could also block the anti-apoptotic action of TNF, leading to increased neutrophil apoptosis helping to fasten the removal of neutrophils. It would be interesting to study the additive effect of TNF- and IGF1-blocking antibodies.

Since IGF1 did not modulate cell surface expression of Fas or Fas-mediated cleavage of full caspase-8, we conclude that
IGF1 does not act at the level of Fas signaling at the plasma membrane. In contrast, IGF1 delays the destabilization of the mitochondrial membrane in the presence of $\mathrm{CH} 11$. Depolarization of the mitochondrial membrane potential is regulated by BCL2 family proteins. Anti-apoptotic members of this family interact with the outer membrane serving to keep its integrity. In contrast, pro-apoptotic members trigger membrane depolarization, in part, through sequestration of anti-apoptotic BCL2 proteins. We hypothesize that IGF1, at least in part, inhibits neutrophil apoptosis through regulation of BCL2 family proteins. It should be noted that the relative effect of IGF1 on the fraction of cells exhibiting mitochondrial membrane depolarization is smaller than the effect on the fraction of apoptotic cells (Figs 1C and 4B). Therefore, the possibility exists that IGF1 also affects apoptosis through regulation of other processes, e.g. activation of inhibitors of apoptosis such as X-linked inhibitor of apoptosis (XIAP), cellular inhibitor of apoptosis protein 1 (BIRC2), cellular inhibitor of apoptosis protein 2 (BIRC3) or survivins that are present in neutrophil ( $\mathrm{Hu} \&$ Sayeed 2005, Martinelli et al. 2006). These molecules are able to inhibit caspase-3 activation without affecting caspase- 8 and mitochondrial membrane potential.

Several protein kinase cascades that can be activated upon IGF1 binding to the IGF1R have been defined (Le Roith et al. 2001). Ligand binding to the extracellular $\alpha$-subunits leads to phosphorylation of the $\beta$-subunits and subsequent association of adapter molecules such as insulin receptor substrates and the Src homology 2 domain containing transforming protein SHC, which serve to recruit other signaling molecules. Recruitment of the $85 \mathrm{kD}$ a regulatory subunit of PI3K results in the activation of the enzyme to phosphorylate phosphatidylinositol biphosphate (PIP2) at the 3-position to generate PIP3. Another pathway that emerges after tyrosine phosphorylation of the IGF1R involves the activation of MAPK3 and MAPK1, through the recruitment of Grb2 and subsequent activation of ras, raf, and MEK. Although it has been established that the PI3K is an important player in regulating neutrophil apoptosis (Cowburn et al. 2002, Yang et al. 2003), the MEK-MAPK1 pathway has also been implicated in this process (Klein et al. 2001, Sheth et al. 2001, Gardai et al. 2004, Kooijman 2006). We therefore established the effects of IGF1 in the presence of the MEK inhibitor U0126 and the PI3K inhibitor wortmannin. It appeared that the MEK-MAPK1 pathway was not involved, whereas inhibition of the PI3K pathway completely abrogated the inhibitive effect of IGF1. Remarkably, IGF1 did not stimulate the phosphorylation or translocation to the membrane of AKT, indicating IGF1 delays neutrophil apoptosis through other PI3K-dependent molecules. In contrast, CSF2, which also delays neutrophil apoptosis via the activation of PI3K (Klein et al. 2000), did induce phophorylation and translocation of AKT.

We also showed that CSF2 inhibits caspase- 8 degradation, which is in line with the observation that CSF2 attenuates the recruitment of FADD to the DISC of Fas (KotoneMiyahara et al. 2004) and subsequent activation of caspase- 8 
(Watson et al. 1999). This process was also shown to be PI3K dependent. These findings implicate that the inhibition of apoptosis by CSF2 involves in part other signaling pathways than those used by IGF1. This could explain additional effects of CSF2 and IGF1 on neutrophil apoptosis presented in Fig. 2A. PI3K has several downstream targets other than AKT which may be involved in the inhibition by IGF1 of neutrophil apoptosis, including protein kinase $\mathrm{C}$ delta (PRKCD) and TEC kinases (Takesono et al. 2002). It has been demonstrated that IFNB1 inhibits apoptosis by PRKCD activation through the PI3K pathway (Wang et al. 2003). However, the protein kinase C inhibitors GFX109203 and rottlerin did not affect the anti-apoptotic effects of IGF1 (data not shown). Identification of PI3K downstream targets involved in neutrophil apoptosis may lead to the discovery of new compounds able to regulate inflammatory processes through the modulation of neutrophil survival. Alternatively, neutrophil survival could be influenced by the components of the IGF1 system or IGF1R antagonists.

\section{Declaration of interest}

The authors have nothing to disclose.

\section{Funding}

This research has been funded by the Flemish Government (GOA 97-02-4), the Fund for Scientific Research-Flanders (F.W.O. G.0041.02), and institutional grants from the VUB.

\section{Acknowledgements}

We are grateful to Eli Lilly for providing rhIGF1.

\section{References}

Abboud SL, Bethel CR \& Aron DC 1991 Secretion of insulin-like growth factor I and insulin-like growth factor-binding proteins by murine bone marrow stromal cells. Journal of Clinical Investigation 88 470-475.

Aprikyan AAG, Liles WC, Park JR, Jonas M, Chi EY \& Dale DC 2000 Myelokathexis, a congenital disorder of severe neutropenia characterized by accelerated apoptosis and defective expression of bcl-x in neutrophil precursors. Blood 95 320-327.

Aprikyan AAG, Liles WC, Rodger E, Jonas M, Chi EY \& Dale DC 2001 Impaired survival of bone marrow hematopoietic progenitor cells in cyclic neutropenia. Blood 97 147-153.

Aprikyan AAG, Liles WC, Boxer LAM \& Dale DCM 2002 Mutant Elastase in pathogenesis of cyclic and severe congenital neutropenia. Journal of Pediatric Hematology/Oncology 24 784-786.

Arkins S, Rebeiz N, Biragyn A, Reese DL \& Kelley KW 1993 Murine macrophages express abundant insulin-like growth factor-I class I Ea and Eb transcripts. Endocrinology 133 2334-2343.

Arkins S, Rebeiz N, Brunke-Reese DL, Biragyn A \& Kelley KW 1995 Interferon-gamma inhibits macrophage insulin-like growth factor-I synthesis at the transcriptional level. Molecular Endocrinology 9 350-360.

Bjerknes R \& Aarskog D 1995 Priming of human polymorphonuclear neutrophilic leukocytes by insulin-like growth factor I: increased phagocytic capacity, complement receptor expression, degranulation, and oxidative burst. Journal of Clinical Endocrinology and Metabolism $\mathbf{8 0}$ 1948-1955.

Cassatella MA 1999 Neutrophil-derived proteins: selling cytokines by the pound. Advances in Immunology 73 369-509.

Colotta F, Re F, Polentarutti N, Sozzani S \& Mantovani A 1992 Modulation of granulocyte survival and programmed cell death by cytokines and bacterial products. Blood 80 2012-2020.

Cowburn AS, Cadwallader KA, Reed BJ, Farahi N \& Chilvers ER 2002 Role of PI3-kinase-dependent Bad phosphorylation and altered transcription in cytokine-mediated neutrophil survival. Blood 100 2607-2616.

Cowburn AS, Deighton J, Walmsley SR \& Chilvers ER 2004 The survival effect of TNF- $\alpha$ in human neutrophils is mediated via NF- $\kappa$ B-dependent IL-8 release. European Journal of Immunology 34 1733-1743.

Firth SM \& Baxter RC 2002 Cellular actions of the insulin-like growth factor binding proteins. Endocrine Reviews 23 824-854.

Fournier T, Riches DWH, Winston BW, Rose DM, Young SK, Noble PW, Lake FR \& Henson PM 1995 Divergence in macrophage insulin-like growth factor-I (IGF-I) synthesis induced by TNF- $\alpha$ and prostaglandin $\mathrm{E}_{2}$. Journal of Immunology 155 2123-2133.

Fu YK, Arkins S, Wang BS \& Kelley KW 1991 A novel role of growth hormone and insulin-like growth factor-I. Priming neutrophils for superoxide anion secretion. Journal of Immunology 146 1602-1608.

Gardai SJ, Whitlock BB, Xiao YQ, Bratton DB \& Henson PM 2004 Oxidants inhibit ERK/MAPK and prevent its ability to delay neutrophil apoptosis downstream of mitochondrial changes and at the level of XIAP. Journal of Biological Chemistry 279 44695-44703.

Gibson TL \& Cohen P 1999 Inflammation-related neutrophil proteases, cathepsin $\mathrm{G}$ and elastase, function as insulin-like growth factor binding protein proteases. Growth Hormone and IGF Research 9 241-253.

Heinisch IV, Daigle I, Knopfli B \& Simon HU 2000 CD137 activation abrogates granulocyte-macrophage colony-stimulating factor-mediated anti-apoptosis in neutrophils. European Journal of Immunology 30 3441-3446.

$\mathrm{Hu}$ Z \& Sayeed MM 2005 Activation of PI3-kinase/PKB contributes to delay in neutrophil apoptosis after thermal injury. American Journal of Physiology. Cell Physiology 288 1171-1178.

Isaacs JD 2008 Therapeutic T-cell manipulation in rheumatoid arthritis: past, present and future. Rheumatology ken163 (In press).

Iwai K, Miyawaki T, Takizawa T, Konno A, Ohta K, Yachie A, Seki H \& Taniguchi N 1994 Differential expression of bcl-2 and susceptibility to antiFas-mediated cell death in peripheral blood lymphocytes, monocytes, and neutrophils. Blood 84 1201-1208.

Iwase M, Takaoka S, Uchida M, Kondo G, Watanabe H, Ohashi M \& Nagumo M 2006 Accelerative effect of a selective cyclooxygenase-2 inhibitor on Fas-mediated apoptosis in human neutrophils. International Immunopharmacology 6 334-341.

Kawakami A, Nakashima T, Tsuboi M, Urayama S, Matsuoka N, Ida H, Kawabe Y, Sakai H, Migita K, Aoyagi T et al. 1998 Insulin-like growth factor I stimulates proliferation and Fas-mediated apoptosis of human osteoblasts. Biochemical and Biophysical Research Communications 247 46-51.

Kettritz R, Gaido ML, Haller H, Luft FC, Jennette CJ \& Falk RJ 1998 Interleukin-8 delays spontaneous and tumor necrosis factor alpha mediated apoptosis of human neutrophils. Kidney International 53 84-91.

Kirstein M, Aston C, Hintz R \& Vlassara H 1992 Receptor-specific induction of insulin-like growth factor-I in human monocytes by advanced glycosylation end product-modified proteins. Journal of Clinical Investigation 90 439-446.

Klein JB, Rane MJ, Scherzer JA, Coxon PY, Kettritz R, Mathiesen JM, Buridi A \& McLeish KR 2000 Granulocyte-macrophage colony-stimulating factor delays neutrophil constitutive apoptosis through phosphoinositide 3-kinase and extracellular signal-regulated kinase pathways. Journal of Immunology 164 4286-4291.

Klein JB, Buridi A, Coxon PY, Rane MJ, Manning T, Kettritz R \& McLeish KR 2001 Role of extracellular signal-regulated kinase and phosphatidylinositol-3 kinase in chemoattractant and LPS delay of constitutive neutrophil apoptosis. Cellular Signalling 13 335-343.

Kobayashi S, Yamashita K, Takeoka T, Ohtsuki T, Suzuki Y, Takahashi R, Yamamoto K, Kaufmann SH, Uchiyama T, Sasada M et al. 2002 
Calpain-mediated X-linked inhibitor of apoptosis degradation in neutrophil apoptosis and its impairment in chronic neutrophilic leukemia. Journal of Biological Chemistry 277 33968-33977.

Kooijman R 2006 Regulation of apoptosis by insulin-like growth factor (IGF)-I. Cytokine and Growth Factor Reviews 17 305-323.

Kooijman R, Berus D, Malur A, Delhase M \& Hooghe-Peters EL 1997 Human neutrophils express GH-N gene transcripts and the pituitary transcription factor Pit-1b. Endocrinology 138 4481-4484.

Kooijman R, Coppens A \& Hooghe-Peters EL 2002 Insulin-like growth factor-I inhibits spontaneous apoptosis in human granulocytes. Endocrinology 143 1206-1212.

Kotone-Miyahara Y, Yamashita K, Lee KK, Yonehara S, Uchiyama T, Sasada M \& Takahashi A 2004 Short-term delay of Fas-stimulated apoptosis by GM-CSF as a result of temporary suppression of FADD recruitment in neutrophils: evidence implicating phosphatidylinositol 3-kinase and MEK1-ERK1/2 pathways downstream of classical protein kinase C. Journal of Leukocyte Biology 76 1047-1056.

Krein PM, Sabatini PJB, Tinmouth W, Green FHY \& Winston BW 2003 Localization of insulin-like growth factor-I in lung tissues of patients with fibroproliferative acute respiratory distress syndrome. American Journal of Respiratory and Critical Care Medicine 167 83-90.

Liles WC, Kiener PA, Ledbetter JA, Aruffo A \& Klebanoff SJ 1996 Differential expression of Fas (CD95) and Fas ligand on normal human phagocytes: implications for the regulation of apoptosis in neutrophils. Journal of Experimental Medicine 184 429-440.

Maianski NA, Maianski AN, Kuijpers TW \& Roos D 2004 Apoptosis of neutrophils. Acta Haematologica 111 56-66.

Martinelli S, Kostylina G, Niggli V, Baumann C, Fey MF, Wendel HG, Lowe SW, Yousefi S \& Simon HU 2006 Targeting survivin via PI3K but not c-akt//PKB by anticancer drugs in immature neutrophils. Oncogene $\mathbf{2 5}$ 6915-6923.

Matsumoto T, Gargosky SE, Iwasaki K \& Rosenfeld RG 1996 Identification and characterization of insulin-like growth factors (IGFs), IGF-binding proteins (IGFBPs), and IGFBP proteases in human synovial fluid. Journal of Clinical Endocrinology and Metabolism 81 150-155.

Mitsiades CS, Poulaki V \& Mitsiades N 2003 The role of apoptosis-inducing receptors of the tumor necrosis factor family in thyroid cancer. Journal of Endocrinology 178 205-216.

Murray J, Barbara JA, Dunkley SA, Lopez AF, Van O X, Condliffe AM, Dransfield I, Haslett C \& Chilvers ER 1997 Regulation of neutrophil apoptosis by tumor necrosis factor-alpha: requirement for TNFR 55 and TNFR75 for induction of apoptosis in vitro. Blood 90 2772-2783.

Noble PW, Lake FR, Henson PM \& Riches DWH 1993 Hyaluronic activation of CD44 induces insulin-like growth factor- 1 expression by a tumor necrosis factor-a-dependent mechanism in murine macrophages. Journal of Clinical Investigation 91 2368-2377.

Nyman T \& Pekonen F 1993 The expression of insulin-like growth factors and their binding proteins in normal human lymphocytes. Acta Endocrinologica 128 168-172.

Le Roith D, Bondy C, Yakar S, Liu JL \& Butler A 2001 The somatomedin hypothesis: 2001. Endocrine Reviews 22 53-74.
Rom WN, Basset P, Fells GA, Nukiwa T, Trapnell BC \& Crystal RG 1988 Alveolar macrophages release an insulin-like growth factor I- type molecule. Journal of Clinical Investigation 82 1685-1693.

Savill J 1997 Apoptosis in resolution of inflammation. Journal of Lenkocyte Biology 61 375-380.

Sheth K, Friel J, Nolan B \& Bankey P 2001 Inhibition of p38 mitogen activated protein kinase increases lipopolysaccharide induced inhibition of apoptosis in neutrophils by activating extracellular signal-regulated kinase. Surgery 130 242-248.

Simon HU 2003 Neutrophil apoptosis pathways and their modifications in inflammation. Immunological Reviews 193 101-110.

Szodoray P, Jellestad S, Nakken B, Brun J \& Jonsson R 2003 Programmed cell death in rheumatoid arthritis peripheral blood T-cell subpopulations determined by laser scanning cytometry. Laboratory Investigation $\mathbf{8 3}$ 1839-1848.

Takesono A, Finkelstein LD \& Schwartzberg PL 2002 Beyond calcium: new signaling pathways for Tec family kinases. Journal of Cell Science $\mathbf{1 1 5}$ 3039-3048.

Tu W, Cheung PT \& Lau YL 2000 Insulin-like growth factor 1 promotes cord blood $\mathrm{T}$ cell maturation and inhibits its spontaneous and phytohemagglutinin-induced apoptosis through different mechanisms. Journal of Immunology 165 1331-1336.

Walsh PT \& O'Connor R 2000 The insulin-like growth factor-I receptor is regulated by CD28 and protects activated T cells from apoptosis. European Journal of Immunology 30 1010-1018.

Wang K, Scheel-Toellner D, Wong SH, Craddock R, Caamano J, Akbar AN, Salmon M \& Lord JM 2003 Inhibition of neutrophil apoptosis by type 1 IFN depends on cross-talk between phosphoinositol 3-kinase, protein kinase C-delta, and NF- $\kappa$ B signaling pathways. Journal of Immunology 171 1035-1041.

Watson RW, O'Neill A, Brannigen AE, Coffey R, Marshall JC, Brady HR \& Fitzpatrick JM 1999 Regulation of Fas antibody induced neutrophil apoptosis is both caspase and mitochondrial dependent. FEBS Letters 453 $67-71$

Wipke BT \& Allen PM 2001 Essential role of neutrophils in the initiation and progression of a murine model of rheumatoid arthritis. Journal of Immunology $1671601-1608$.

Wynes MW \& Riches DW 2003 Induction of macrophage insulin-like growth factor-I expression by the Th2 cytokines IL-4 and IL-13. Journal of Immunology 171 3550-3559.

Yang KY, Arcaroli J, Kupfner J, Pitts TM, Park JS, Strasshiem D, Perng RP \& Abraham E 2003 Involvement of phosphatidylinositol 3-kinase gamma in neutrophil apoptosis. Cellular Signalling 15 225-233.

Received in final form 3 July 2008

Accepted 24 July 2008

Made available online as an Accepted Preprint

24 July 2008 